\title{
Maternal and Cord Blood Saturated Fatty Acid Level and Infant Adiposity
}

\author{
Yustiyani $^{1,2}$, Faisal Anwar ${ }^{2}$, Mira Dewi ${ }^{2,3^{*}}$ \\ ${ }^{1}$ Public Health Study Program, Faculty of Health Sciences, UIN Syarif Hidayatullah Jakarta, \\ South Tangerang 15419, Indonesia \\ ${ }^{2}$ Department of Community Nutrition, Faculty of Human Ecology, IPB University, Bogor 16680, Indonesia \\ ${ }^{3}$ South East Asian Food and Agricultural Science and Technology (SEAFAST) Center, IPB University, \\ Bogor 16680, Indonesia
}

\begin{abstract}
This study aimed to assess SFAs profiles in the maternal and cord blood, and the relationship of both SFAs levels with infant adiposity. As many as 99 mothers with singleton pregnancy and pre-pregnancy $\mathrm{BMI} \geq 18.5$ agreed to join the research and completed the data collection process. Maternal and cord blood erythrocyte SFAs profile was analyzed using Gas Chromatography-Flame Ionized Detector. Infant birth weight was measured at birth, while infant skinfolds were at 5-7 days postpartum. We used Aris et al. (2013) equation to assess the infant fat mass. The average maternal age was $29.62 \pm 5.84$ years old, while the pre-pregnancy BMI was $22.87 \pm 3.90 \mathrm{~kg} / \mathrm{m}^{2}$. Infant birth weight was $3168.83 \pm 341.64 \mathrm{~g}$, and fat mass was $9.39 \pm 3.52 \%$. Maternal total SFAs and palmitic acid (C16:0) concentration were higher than cord blood, while lignoceric acid $(\mathrm{C} 24: 0)$ was lower $(\mathrm{p}<0.05)$. Increased maternal caproic $(\mathrm{C} 6: 0)$, capric $(\mathrm{C} 10: 0)$, and lauric acids $(\mathrm{C} 12: 0)$ were associated with higher infant adiposity $(\mathrm{p}<0.05)$. Total SFAs, palmitic (C16:0), stearic (C18:0), and behenic acids (C22:0) in cord blood were negatively associated with infant adiposity $(\mathrm{p}<0.05)$. Elevated lauric $(\mathrm{C} 12: 0)$ and myristic $(\mathrm{C} 14: 0)$ acids in cord blood were associated with greater adiposity. In conclusion, we found a different SFAs profile between maternal blood during the third trimester of pregnancy and cord blood. Increased maternal caproic, capric, and lauric acids as well as cord blood's lauric and palmitic acids contribute to greater infant adiposity.
\end{abstract}

Keywords: cord blood, fat mass, infant adiposity, pregnant women, saturated fatty acids

\section{INTRODUCTION}

Obesity has been growing nutrition problem affecting both the adult and children population in Indonesia. In 2018, the national prevalence of childhood obesity reached $8 \%$ (MoH RI 2018). Determinants of Childhood obesity in developing countries are multifaceted, some are unhealthy diet (fast food consumption), physical inactivity, socioeconomic status, area of residency, age, gender (Gupta et al. 2012; Febriani $\&$ Sudiarti 2019). Recent evidence suggests that childhood obesity could also be predicted at birth by early Fat Mass (FM) deposition or neonatal adiposity (Moore et al. 2020). Excess neonatal adiposity is associated with an adverse health outcome in the future life. Hernandez-Trejo et al. (2020) showed that it might increase the pro-inflammatory cytokine levels at birth. Later during the childhood period, it contributes to the incidence of inflammatory diseases, such as atopic dermatitis (O'Donovan et al. 2016).

The adipose tissue serves as an energy storage and thermoregulator among mammals, including in human infant. Interestingly, it also acts as an endocrine organ which modulates a range of metabolic pathways and inflammation process. The human body will deposit energy surplus as triglyceride in adipose tissue through the lipogenic pathway. Conversely, when the body experiences energy scarcity, the lipolytic process will break the triglyceride deposit in adipose tissue down into glycerol and fatty acids. The released glycerol and fatty acids will be distributed to muscle and other organs and modulate the energy balance throughout the body (Luo \& Liu 2016). It is a crucial mechanism to protect the infant from energy shortfall when breastfeeding has not been established yet, or during the transition to weaning food.

\footnotetext{
"Corresponding Author: tel: +6281280898599, email: mirade@apps.ipb.ac.id

(Received 01-05-2021; Accepted 15-07-2021; Published 29-07-2021)
} 
On the other side, adipose tissue can maintain infant body temperature through non-shivering thermogenesis. This is an important mechanism since muscle function in new-born has not fully developed, making them unable to raise body temperature through shivering (Lichtenbelt \& Schrauwen 2011).

SFAs is the most abundance component of lipid which play a major part on lipid metabolism in human body. However, evidence depicting the role of SFAs on neonatal adiposity are inconsistent and limited. Mennitti et al. (2015) reviewed several animal studies which concluded that excessive SFAs intake may lead to the development metabolic disease and obesity. Moore et al. (2018) studied the dietary pattern among pregnant women and concluded that intake of saturated fat contributed to higher dietary inflammatory index. This study further demonstrated that elevated dietary inflammatory index and pre-pregnancy Body Mass Index (BMI) increased the odds of large-for-gestational age infant. However, growing body of evidence also suggests that increased concentration of certain SFAs is not necessarily associated with increased adiposity. A recent study among Singaporean infants shows that Medium-Chain Fatty Acids (MCFA) are associated with lower infant skinfold thickness (Chia et al. 2020). MCFAs increases the intrinsic respiratory capacity of mitochondria which is beneficial to prevent lipid accumulation in adipose tissue (Montgomery et al. 2013).

The peak of the lipid accumulation process in infants happens during the third trimester of pregnancy. In this period, maternal fat deposit going through enhanced lipolysis. Fatty acids from maternal circulation will enter the fetal body through the placenta, and eventually the umbilical cord. The placenta has its regulatory mechanism to select materials that will pass through the fetal body, including fatty acids. Placenta can also perform de novo synthesis of SFAs (ChavanGautam et al. 2018). It suggests that SFAs profile in the placenta and umbilical cord blood is not necessarily similar to that of maternal blood.

Therefore, in this study, we assessed SFAs profiles in the mother's blood during the third trimester of pregnancy and cord blood. The SFAs profile in the cord blood represented the infant compartment. We also evaluated the differences between SFAs profile in maternal and infant compartments. Finally, we investigated whether the SFAs level in maternal and cord blood affect infant adiposity indicators in the early postpartum period.

\section{METHODS}

\section{Design, location and time}

This research was a longitudinal study conducted between May and December 2018 in Bogor City, West Java Province, Indonesia. Some of the data used were taken from a BASF South East Asia grant study entitled "Association of Maternal Dietary Intake and Blood Level of Long Chain Poly-Unsaturated Fatty Acids in Pregnancy and Newborn Body Composition" by IPB's SEAFAST CENTER team. The subject recruitment took place at the North Bogor and Tanah Sareal Public Health Center (PHC). In these two PHCs, the number of pregnant women who visited to receive Antenatal Care (ANC) services was the largest in Bogor. The blood's SFAs profile assessment took place at the DKI Jakarta Regional Health Laboratory. Ethical approval was granted by the Research Ethics Committee of LPPM IPB University (041/IT3. KEPMSM-IPB/SK/2018). Permission to conduct this study was obtained from the district health office of Bogor City, Indonesia.

\section{Sampling}

The study population was pregnant women aged 18-45 years in Bogor City with a gestational age between $32-40$ weeks. The research subjects were third-trimester pregnant women who attended ANC service at the North Bogor and Tanah Sareal PHC from May to September 2018. The inclusion criteria were mothers with singleton pregnancies and had a pre-pregnancy BMI of more than or equal to 18.5 $\mathrm{kg} / \mathrm{m}^{2}$. As many as 142 pregnant women who met the criteria agreed to participate in the study and provide informed consent. Out of 142 subjects recruited, only 99 complete data were available for analysis. The remaining 43 maternal-infant dyad could not be included in the analysis due to unavailable maternal blood samples (17 subjects), lost to follow up (11 subjects), self-withdrawal (7 subjects), gave birth at different hospital (4 subjects), and cord blood hemolysis (4 subjects).

\section{Data collection}

The data used in this study consisted of maternal characteristics (age, parity, pre- 


\section{Maternal and cord blood saturated fatty acid}

pregnancy BMI, Mid-upper Arm Circumference/ MUAC), maternal and cord blood SFA levels, infant characteristics and nutritional status (sex, birth weight, and triceps, subscapular and thigh skinfolds). Interviews and infant skinfolds measurement was carried out at the $\mathrm{PHC}$ or the subject's homes by trained enumerators. The laboratory staff collected maternal blood samples, while the midwives collected the cord blood samples. The laboratory staff performed the preparation of all blood samples in the PHC. Data on maternal (MUAC, pre-pregnancy weight, height) and infant Birth Weight (BW) and birth history were obtained from the PHC birth register book and the maternal and child health (KIA) book.

The enumerators, midwives, and laboratory staff received a set of training program before the data collection. The enumerator training consisted of recruitment procedures, interviews, and infant anthropometric measurement techniques. The training courses for laboratory staff and midwives consisted of the screening process of potential subjects, maternal and cord blood drawing, and blood preparation techniques.

Data collection consisted of two stages. The first stage was subjects recruitment. After receiving the signed informed consent, trained enumerators collected data on the characteristics and nutritional status of the subject through interviews using a structured questionnaire. The second stage was a home visit by enumerators on 5-14 days postpartum to collect data on birth history and skinfolds of the infants. The BW measurement of the baby were recorded in the PHC's birth registers book where the baby's delivery process took place. A trained midwife took this measurement right after the baby was born. The infant's triceps, subscapular and thigh skinfold was measured directly by trained enumerators at the subject's house at 5-14 days postpartum using Lange ${ }^{\circledR}$ body caliper. The skinfolds thickness measurement were taken twice at each site to ensure the data quality.

The cubital venous blood samples of the subjects were taken at the first visit or after the recruitment process, while the venous cord blood was right after the delivery process. The blood sample was stored in an EDTA tube and centrifuged within 12 hours after blood withdrawal. The erythrocyte portion was taken and stored in a labeled plastic container at $-80^{\circ} \mathrm{C}$ until further analysis. The fatty acids in erythrocytes were extracted and analyzed using the modified Folch et al. (1957) method. The fatty acids profile was measured using Gas Chromatography-Flame Ionization Detector (GC-FID) by professional laboratory staff at the DKI Jakarta Regional Health Laboratory.

\section{Data analysis}

Pre-pregnancy Body Mass Index (BMI) was calculated based on maternal pre-pregnancy weight and height data. We used the following equation (Aris et al. 2013) to calculate the newborn FM:

$\mathrm{FM}=-0.022+\left(0.307^{*} \mathrm{~W}\right)-\left(0.077^{*} \mathrm{G}\right)-$ $\left(0.019^{*} \mathrm{GA}\right)+\left(0.028^{*} \mathrm{SSF}\right)$

FM: Fat Mass $(\mathrm{kg})$

GA: Gestational Age (weeks)

G: Gender ( $1=$ male; $0=$ female $)$

SSF: Subscapular Skin Fold (mm)

W: Birth Weight $(\mathrm{kg})$

The data processing and analysis were conducted using Microsoft Excel 2019 and SPSS version 25.0 software. Continuous data were presented descriptively as mean and standard for normally distributed data. Median and Interquartile Range (IQR) information was also added for non-normally distributed data. Paired sample t-test was employed to assess the mean difference between maternal and cord blood profile. We used Pearson correlation test to identify correlation of maternal and cord blood SFA profile with infant weight, triceps, subscapular, and thigh skinfolds, and FM percentage. The significant level was set at $\mathrm{p}<0.05$ for all tests.

\section{RESULTS AND DISCUSSION}

\section{Maternal and infant's characteristics}

Table 1 shows the maternal and infant characteristics. Subjects were pregnant women between 20 and 45 years old. Most of the subjects have normal nutrition status (BMI 18.5-24.9 kg/ $\mathrm{m}^{2}$ ) before their pregnancy $(76.8 \%)$. The average gestational age at delivery was $39.23 \pm 1.20$ weeks. The proportion of female and male infants are quite similar $(50.5 \%)$ for female and $(49.5 \%)$ male respectively. The average BW of the infants were $3168.83 \pm 341.64 \mathrm{~g}$. The FM percentage in this study $(9.39 \pm 3.52 \%)$ was lower than the reported FM of infant from Asian mothers (Wiechers et al. 2019). 
Yustiyani et al.

Table 1. Maternal and infant characteristics $(\mathrm{n}=99)$

\begin{tabular}{|c|c|c|}
\hline Variables & $\mathrm{n}(\%)$ & Mean \pm SD \\
\hline \multicolumn{3}{|l|}{ Maternal characteristics } \\
\hline Age (years) & & $29.62 \pm 5.84$ \\
\hline $20-29$ & $51(51.5)$ & \\
\hline $30-39$ & $42(42.4)$ & \\
\hline $40-45$ & $6(6)$ & \\
\hline PP-BMI $\left(\mathrm{kg} / \mathrm{m}^{2}\right)$ & & $22.87 \pm 3.90$ \\
\hline $18.5-24.9$ & $76(76.8)$ & \\
\hline$\geq 25$ & $23(23.2)$ & \\
\hline MUAC (cm) & $99(100)$ & \\
\hline $\begin{array}{l}\text { Gestational age at delivery } \\
\text { (weeks) }\end{array}$ & & $27.01 \pm 2.96$ \\
\hline Infant characteristics & & $39.23 \pm 1.20$ \\
\hline \multicolumn{3}{|l|}{ Gender } \\
\hline Female & $50(50.5)$ & \\
\hline Male & 49 (49.5) & \\
\hline Birth weight (g) & & $3168.83 \pm 341.64$ \\
\hline Tricep skinfold (mm) & & $4.87 \pm 1.55$ \\
\hline Subscapula skinfold (mm) & & $4.99 \pm 1.69$ \\
\hline Tigh skinfold (mm) & & $5.57 \pm 1.63$ \\
\hline Fat mass $(\%)$ & & $9.39 \pm 3.52$ \\
\hline
\end{tabular}

\section{Maternal and cord blood' SFA profile}

Table 2 shows total SFA and ten individual SFAs measured in maternal and umbilical cord red blood cell samples. Total SFAs and palmitic acid (C16:0) concentration in maternal blood were significantly higher than cord blood $(\mathrm{p}=0.001)$. On the contrary, lignoceric acid (C24:0) concentration in cord blood was notably higher than maternal blood $(p=0.000)$. It indicates that maternal blood SFA profile might not be similar to cord blood. Placenta, which connects the maternal and infant compartment, regulates fatty acids transfer to the fetus. Evidence suggests that compared to SFAs, placental plasma membrane binding sites have a strong preference for LongChain Polyunsaturated Fatty Acids (LCPUFAs), such as arachidonic acid, docosahexaenoic acid, and eicosapentaenoic acid (Duttoray \& Bassak 2020). It may explain the decrease of total SFAs and palmitic acid (C16:0) concentration in cord blood.
Lignoceric acid (C24:0) is a longchain saturated fatty acid, which can be found throughout the human body. It is one of the most common fatty acids bonded into the ceramide backbone to form sphingolipid. The lignocericacid-containing-sphingolipid mainly appears in axons of neuron cells in the liver, kidney, pancreas, and brown and white adipose tissue (Sassa \& Kihara 2014). Increased lignoceric acid (C24:0) concentration in cord blood might suggest that this component came from maternal circulation and placenta. The placenta can produce its SFAs through the de novo synthesis process (ChavanGautam et al. 2018).

Palmitic and stearic acid universally are found in natural fats. In this study, palmitic acid (C16:0) concentration was the highest among other SFAs in maternal and cord blood (Table 2). These findings are in line with previous studies which stated that palmitic acid is the principal constituent of fatty acids found in human tissues, such as in serum (Liu et al. 2017; Yammine et al. 2018), red blood cell (Aktas et al. 2016), adipose tissue (Shramko et al. 2020) and other human tissues in general (Ruiz-Nunez et al. 2016). This pattern remains consistent when compared to Spanish vegetarian population (Salvador et al. 2019), and Italian or Tibetan population (Rise et al. 2008) whose main dietary oil is olive, sunflower, mustard, canola, and corn oil. It might also important to note that the human body also synthesizes SFAs through de novo synthesis, which its main products is palmitic $(\mathrm{C16:0)}$ and stearicacid(C18:0)(Chauvan-Gautametal.2018).

\section{Association between maternal and cord blood SFA and infant adiposity}

The correlation between high blood levels of SFAs and increased adiposity was well documented in a previous study (Yammine et al. 2018). Table 3 shows the association of maternal SFAs concentration with infant adiposity indicator (BW, FM percentage, tricep, subscapular, and thigh skinfolds). Lauric acid (C12:0) concentration was positively associated with all adiposity indicators $(\mathrm{p}<0.05)$. Caproic acid (C6:0) concentration was positively associated with tricep, subscapular, and thigh skinfolds $(\mathrm{p}<0.05)$. Capric acid $(\mathrm{C} 10: 0)$ was positively associated with tricep and thigh skinfolds.

Increasing evidence suggests that increased infant adiposity highly correlates with maternal 
Maternal and cord blood saturated fatty acid

Tabel 2. Maternal and Cord Blood' SFA profile ( $\mathrm{n}=99$ )

\begin{tabular}{|c|c|c|c|c|c|}
\hline \multirow{2}{*}{ Fatty acid } & \multicolumn{2}{|c|}{ Maternal blood (g/100 g fatty acid) } & \multicolumn{2}{|c|}{ Cord blood (g/100 g fatty acid) } & \multirow{2}{*}{$\mathrm{p}$} \\
\hline & Mean \pm SD & Median (IQR) & Mean \pm SD & Median (IQR) & \\
\hline Total SFA & $24.78 \pm 13.27$ & $28.29(14.45-33.26)$ & $21.09 \pm 16.16$ & $23.74(3.06-33.43)$ & $0.001^{*}$ \\
\hline C6:0 & $2.93 \pm 5.65$ & $0.55(0.17-2.07)$ & $3.08 \pm 6.30$ & $0.44(0.08-2.27)$ & 0.364 \\
\hline C8:0 & $0.13 \pm 0.32$ & $0.02(0.00-0.07)$ & $0.30 \pm 0.70$ & $0.06(0.01-0.23)$ & 0.532 \\
\hline C10:0 & $0.38 \pm 0.85$ & $0.06(0.03-0.23)$ & $0.41 \pm 0.79$ & $0.10(0.02-0.32)$ & 0.584 \\
\hline $\mathrm{C} 12: 0$ & $0.44 \pm 1.01$ & $0.10(0.03-0.28)$ & $0.34 \pm 0.68$ & $0.09(0.02-0.24)$ & 0.536 \\
\hline $\mathrm{C} 14: 0$ & $0.31 \pm 0.24$ & $0.31(0.10-0.44)$ & $0.93 \pm 1.99$ & $0.28(0.07-0.62)$ & 0.526 \\
\hline $\mathrm{C} 16: 0$ & $23.72 \pm 13.06$ & $26.03(14.30-30.99)$ & $19.57 \pm 15.71$ & $22.46(1.29-31.99)$ & $0.001^{*}$ \\
\hline C18:0 & $0.29 \pm 0.65$ & $0.09(0.01-0.19)$ & $0.47 \pm 1.77$ & $0.11(0.01-0.29)$ & 0.744 \\
\hline $\mathrm{C} 20: 0$ & $0.23 \pm 0.59$ & $0.00(0.00-0.05)$ & $0.67 \pm 2.18$ & $0.03(0.00-0.09)$ & 0.482 \\
\hline $\mathrm{C} 22: 0$ & $0.40 \pm 0.90$ & $0.15(0.01-0.34)$ & $0.17 \pm 0.35$ & $0.02(0.01-0.26)$ & 0.982 \\
\hline $\mathrm{C} 24: 0$ & $0.15 \pm 0.48$ & $0.00(0.00-0.01)$ & $0.21 \pm 0.69$ & $0.01(0.00-0.03)$ & $0.000^{*}$ \\
\hline
\end{tabular}

C6:0: Caproic Acid; C8:0: Caprylic Acid; C10:0: Capric Acid; C12:0: Lauric Acid; C14:0: Myristic Acid; C16:0: Palmitic Acid; C18:0: Stearic Acid; C20:0: Arachidic Acid; C22:0: Behenic Acid; C24:0: Lignoceric Acid; IQR: Inter Quartile Range (quartile 1-quartile 3); SFA: Saturated Fatty Acid; SD: Standard Deviation

* $\mathrm{p}<0.05$ shows significant mean difference between maternal and cord blood samples

free fatty acids and their triglyceride sources (Barbour \& Hernandez 2018). Lauric acid (C12:0), one of the long-chain SFA, is less prone to $\beta$-oxidation than the shorter chain SFAs. It also can increase all cholesterol fractions, including triglyceride (Shramko et al. 2020). It may explain the positive association of lauric acid level with infant adiposity indicators.

Compared to long-chain SFAs, mediumchain SFAs (6-12 carbons) is a preferred substrate of $\beta$-oxidation. Medium-chain SFAs are mainly oxidized in the liver, resulting in lower fat deposition in adipose tissue (Ruiz-Nunez et al. 2016). A study in mice also confirmed that compared to long-chain SFAs, mediumchain SFAs increase the mitochondrial intrinsic respiratory capacity without increasing the oxidative stress (Montgomery et al. 2013). However, in this study, we found that increased caproic acid (C6:0) and capric acid (C10:0) correlated with increased infants' skinfolds (Table 3).

The correlation between cord blood SFAs level and infant adiposity is presented in Table 4. Cord blood lauric acid (C12:0) is positively associated with tricep skinfold. This result contradicts previous study which stated that medium-chain SFAs prevent the lipid deposition in adipose tissue tissue (Ruiz-Nunez et al. 2016). Cord blood myristic acid (C14:0) is positively associated with subscapular, thigh skinfolds, and FM percentage. Myristic acid is a long-chain SFAs, which was reported to pose a greater obesogenic effect than other medium and shortchain SFAs (Sergi \& Williams 2020). Long chain fatty acid is one of various nutrients that can easily reach the brain and induce cellular stress or inflammatory responses, mainly via Toll-like receptor 4 (TLR4) during the development of obesity (Mullins et al. 2020).

Total SFAs, palmitic acid (C16:0), stearic acid (C18:0), and behenic acid (C22:0) in cord blood are negatively correlated with infant adiposity indicators (Table 4). These findings are unexpected and inconsistent with previous studies, which suggest that SFAs intake, specifically long-chain SFAs, are associated with obesity (Yammine et al. 2018; Sergi \& Williams 2020). This data, however, was in line with another study which shows that total SFAs, palmitic acid, and stearic acid intake of lean children was significantly higher than that of overweight or obese children (Jauregibeitia et al. 2020). 
Yustiyani et al.

Table 3. Association between maternal blood SFAs and infant adiposity $(\mathrm{n}=99)$

\begin{tabular}{|c|c|c|c|c|c|}
\hline \multirow{2}{*}{ Saturated fatty acid } & \multirow{2}{*}{ Birth weight } & \multicolumn{3}{|c|}{ Skinfolds } & \multirow{2}{*}{$\%$ Fat mas } \\
\hline & & Tricep & Subscapula & Tigh & \\
\hline \multicolumn{6}{|l|}{ Total SFAs } \\
\hline $\mathrm{r}$ & 0.156 & -0.136 & -0.041 & -0.118 & 0.061 \\
\hline $\mathrm{p}$ & 0.123 & 0.181 & 0.687 & 0.244 & 0.549 \\
\hline \multicolumn{6}{|l|}{ Caproic acid (C6:0) } \\
\hline $\mathrm{r}$ & 0.100 & 0.263 & 0.224 & 0.256 & 0.157 \\
\hline $\mathrm{p}$ & 0.323 & $0.009^{*}$ & $0.026^{*}$ & $0.011^{*}$ & 0.122 \\
\hline \multicolumn{6}{|l|}{ Caprylic acid (C8:0) } \\
\hline $\mathrm{r}$ & 0.008 & 0.142 & 0.126 & 0.102 & 0.069 \\
\hline $\mathrm{p}$ & 0.934 & 0.162 & 0.214 & 0.314 & 0.500 \\
\hline \multicolumn{6}{|l|}{ Capric acid (C10:0) } \\
\hline $\mathrm{r}$ & 0.070 & 0.256 & 0.191 & 0.253 & 0.130 \\
\hline $\mathrm{p}$ & 0.488 & $0.011^{*}$ & 0.058 & $0.015^{*}$ & 0.199 \\
\hline \multicolumn{6}{|l|}{ Lauric acid (C12:0) } \\
\hline $\mathrm{r}$ & 0.221 & 0.345 & 0.229 & 0.244 & 0.244 \\
\hline $\mathrm{p}$ & $0.028^{*}$ & $0.000^{*}$ & $0.023^{*}$ & $0.015^{*}$ & $0.015^{*}$ \\
\hline \multicolumn{6}{|l|}{ Myristic acid (C14:0) } \\
\hline $\mathrm{r}$ & 0.010 & -0.076 & -0.044 & -0.113 & -0.021 \\
\hline $\mathrm{p}$ & 0.919 & 0.452 & 0.665 & 0.267 & 0.833 \\
\hline \multicolumn{6}{|l|}{ Palmitic acid (C16:0) } \\
\hline $\mathrm{r}$ & 0.165 & -0.129 & -0.032 & -0.102 & 0.164 \\
\hline $\mathrm{p}$ & 0.104 & 0.205 & 0.751 & 0.316 & 0.105 \\
\hline \multicolumn{6}{|l|}{ Stearic acid (C18:0) } \\
\hline r & -0.127 & -0.087 & -0.057 & -0.173 & -0.121 \\
\hline $\mathrm{p}$ & 0.210 & 0.391 & 0.577 & 0.087 & 0.234 \\
\hline \multicolumn{6}{|l|}{ Arachidic acid (C20:0) } \\
\hline $\mathrm{r}$ & 0.097 & 0.011 & -0.078 & -0.002 & 0.029 \\
\hline $\mathrm{p}$ & 0.337 & 0.916 & 0.443 & 0.983 & 0.774 \\
\hline \multicolumn{6}{|l|}{ Behenic acid (C22:0) } \\
\hline r & 0.013 & -0.037 & 0.017 & -0.080 & 0.074 \\
\hline $\mathrm{p}$ & 0.901 & 0.713 & 0.870 & 0.432 & 0.469 \\
\hline \multicolumn{6}{|l|}{ Lignoceric acid (C24:0) } \\
\hline$r$ & -0.136 & -0.075 & -0.115 & -0.107 & -0.137 \\
\hline $\mathrm{p}$ & 0.180 & 0.459 & 0.256 & 0.291 & 0.177 \\
\hline
\end{tabular}

This study confirmed that several SFAs paramater in maternal blood was associated with infant birth weight, skinfold thickness, and percentage of fat mass. However, it could not explain the mechanism underlying this association. Recent hypothesis suggested that maternal fatty acids enters the fetal circulation through placenta, and they either converted into acyl-CoA in the liver and used there for the synthesis of triaylglicerol or may be taken 


\section{Maternal and cord blood saturated fatty acid}

Table 4. Association between cord blood SFAs and infant adiposity

\begin{tabular}{|c|c|c|c|c|c|}
\hline \multirow{2}{*}{ Saturated fatty acid } & \multirow{2}{*}{ Birth weight } & \multicolumn{3}{|c|}{ Skinfolds } & \multirow{2}{*}{$\%$ Fat mass } \\
\hline & & Tricep & Subscapula & Tigh & \\
\hline \multicolumn{6}{|l|}{ Total SFAs } \\
\hline $\mathrm{r}$ & -0.074 & -0.164 & -0.126 & -0.230 & -0.082 \\
\hline $\mathrm{p}$ & 0.468 & 0.104 & 0.215 & $0.022^{*}$ & 0.419 \\
\hline \multicolumn{6}{|l|}{ Caproic acid (C6:0) } \\
\hline $\mathrm{r}$ & 0.001 & -0.068 & 0.010 & -0.037 & 0.014 \\
\hline $\mathrm{p}$ & 0.995 & 0.506 & 0.925 & 0.714 & 0.888 \\
\hline \multicolumn{6}{|l|}{ Caprylic acid (C8:0) } \\
\hline $\mathrm{r}$ & -0.027 & -0.057 & 0.030 & -0.003 & -0.016 \\
\hline $\mathrm{p}$ & 0.792 & 0.575 & 0.769 & 0.979 & 0.873 \\
\hline \multicolumn{6}{|l|}{ Capric acid (C10:0) } \\
\hline $\mathrm{r}$ & -0.018 & -0.133 & 0.007 & -0.050 & 0.041 \\
\hline $\mathrm{p}$ & 0.858 & 0.189 & 0.944 & 0.625 & 0.684 \\
\hline \multicolumn{6}{|l|}{ Lauric acid (C12:0) } \\
\hline $\mathrm{r}$ & -0.029 & 0.264 & 0.019 & -0.067 & -0.009 \\
\hline $\mathrm{p}$ & 0.777 & $0.008^{*}$ & 0.851 & 0.508 & 0.931 \\
\hline \multicolumn{6}{|l|}{ Myristic acid (C14:0) } \\
\hline $\mathrm{r}$ & 0.058 & -0.141 & 0.258 & 0.207 & 0.209 \\
\hline $\mathrm{p}$ & 0.569 & 0.164 & $0.010^{*}$ & $0.040^{*}$ & $0.038^{*}$ \\
\hline \multicolumn{6}{|l|}{ Palmitic acid (C16:0) } \\
\hline $\mathrm{r}$ & -0.038 & -0.145 & -0.098 & -0.214 & -0.047 \\
\hline $\mathrm{p}$ & 0.710 & 0.153 & 0.335 & $0.034^{*}$ & 0.648 \\
\hline \multicolumn{6}{|l|}{ Stearic acid (C18:0) } \\
\hline r & $-.251^{*}$ & -0.145 & -0.138 & -0.143 & $-.238^{*}$ \\
\hline $\mathrm{p}$ & 0.012 & 0.153 & 0.174 & 0.157 & 0.018 \\
\hline \multicolumn{6}{|l|}{ Arachidic acid (C20:0) } \\
\hline $\mathrm{r}$ & -0.055 & -0.015 & -0.033 & 0.025 & -0.040 \\
\hline $\mathrm{p}$ & 0.587 & 0.885 & 0.746 & 0.803 & 0.692 \\
\hline \multicolumn{6}{|l|}{ Behenic acid (C22:0) } \\
\hline $\mathrm{r}$ & 0.088 & -0.171 & -0.165 & -0.228 & -0.014 \\
\hline $\mathrm{p}$ & 0.386 & 0.090 & 0.103 & $0.023^{*}$ & 0.893 \\
\hline \multicolumn{6}{|l|}{ Lignoceric acid (C24:0) } \\
\hline $\mathrm{r}$ & -0.094 & -0.133 & -0.170 & -0.117 & -0.118 \\
\hline $\mathrm{p}$ & 0.353 & 0.189 & 0.092 & 0.247 & 0.244 \\
\hline
\end{tabular}

up directly by adipocytes (Desoye \& Herrera 2021). It was also hypothesized that the higher maternal fatty acid transfers to fetal circulation, the higher adypocyte generation converted from the mesenchymal stem cells (Szabo 2019).
Reviews on animal studies (Mennitti et al. 2013) concluded that intake of diet rich in SFAs during pregnancy and/or lactation mediated the high proinflammatory cytokines production through the TLR4 pathway activation. This TLR4- 
mediated inflammation acts in the pathogenesis of obesity, which represented by increased body mass, visceral fat and adipocyte hypertrophy.

It has been well understood that infancy is a rapid growth and development period in which massive multiplication of body cells happens. In this process, fatty acids in general serves as energy sources, building blocks of membrane cells, cell division, differentiation and death, cell signaling, etc (Carvalho \& Caramujo 2018). As an energy sources, fat $(9 \mathrm{kcal} / \mathrm{g})$ provides a higher energy than carbohydrate and protein $(4 \mathrm{kcal} / \mathrm{g})$. SFAs could be found as a major component of phospolipid or glycerophospolipid in cellular membranes. Very-long-chain SFA such as lignoceric acid (C24:0) is the most common fatty acids component of sphingomyelin, an important lipid molecules in cell division and differentiation (Sassa \& Kihara 2014; Carvalho \& Caramujo 2018).

SFAs compose a big portion in our dietary fats, especially the palmitic and stearic acids. Moreover, unlike the essential omega- 3 and omega- 6 fatty acids, our body has the ability to synthesize SFAs endogenously. It also attributed to the negative impact of SFAs to human health, such as increased of inflammatory response cardiovascular disease (Ruiz-Nunez et al. 2016), and adiposity as also concluded in the current study. It might be the main reason why the general recommendation in nutritional guidelines is to restrict dietary SFAs intake.

\section{CONCLUSION}

We found a higher total SFAs and lauric acid concentration in maternal blood during the third trimester of pregnancy than in cord blood. Our findings also contribute to the growing body of evidence on the role of SFAs during pregnancy on infant adiposity. Increased maternal caproic, capric, and lauric acids are associated with higher infant adiposity. Elevated lauric and myristic acids in cord blood contribute to greater adiposity. Conversely, increased total SFAs, palmitic, stearic, and behenic acids in cord blood are associated with lower infant adiposity. Further studies exploring the contribution of maternal and infant dietary SFAs are needed to establish a more comprehensive view on the role of SFAs to infant adiposity.

\section{ACKNOWLEDGEMENT}

We thanked SEAFAST Center IPB University and BASF South East Asia for allowing us to use part of the data from their research.

\section{AUTHOR DISCLOSURES}

The authors have no conflict of interest in preparing this manuscript.

\section{REFERENCES}

Aktas M, Elmastas M, Ozcicek F, Yilmaz N. 2016. Erythrocyte membrane fatty acid composition in premenopausal patients with iron deficiency anemia. J Oleo Sci 65 (3):225-231. https://doi.org/10.5650/jos. ess 15211

Aris IM, Soh SE, Tint MT, Liang S, Chinnadurai A, Saw SM, Kwek K, Godfrey KM, Gluckman PD et al. 2013. Body fat in Singaporean Infants: Development of body fat prediction equations in Asian newborns. Eur J Clin Nutr 67(9):922-927. https://doi.org/10.1038/ejen.2013.69

Barbour LA, Hernandez TL. 2018. Maternal lipids and fetal overgrowth: Making fat from fat. Clin Ther 40(10): 1638-1647. https://doi. org/10.1016/j.clinthera.2018.08.007

Carvalho CCR, Caramujo MJ. 2018. The various roles of fatty acids. Molecules 23(10):2583. https://doi.org/10.3390/ molecules 23102583

Chavan-Gautam P, Rani A, Freeman DJ. 2018. Chapter Six - distribution of fatty acids and lipids during pregnancy. Adv Clin Chem 84:209-239. https://doi.org/10.1016/ bs.acc.2017.12.006

Chia AR, de Seymour JV, Wong G, Sulek K, Han TL, McKenzie EJ, Aris IM, Godfrey KM, Yap F, Tan KH et al. 2020. Maternal plasma metabolic markers of neonatal adiposity and associated maternal characteristics: The GUSTO study. Sci Rep 10:9422. https://doi.org/10.1038/s41598-02066026-5

Desoye G, Herrera E. 2021. Adipose tissue development and lipid metabolism in the human fetus: The 2020 perspective focusing on maternal diabetes and obesity. 


\section{Maternal and cord blood saturated fatty acid}

Prog Lipid Res 81:101082. https://doi. org/10.1016/j.plipres.2020.101082

Duttaroy AK, Basak S. 2020. Maternal dietary fatty acids and their roles in human placental development. Prostaglandins Leukot Essent Fatty Acids 155:102080. https:// doi.org/10.1016/j.plefa.2020.102080

Febriani D, Sudiarti T. 2019. Fast food as drivers for overweight and obesity among urban school children at Jakarta, Indonesia. J Gizi Pangan 14(2):99-106. https://doi. org/10.25182/jgp.2019.14.2.99-106

Folch J, Lees M, Sloane-Stanley GH. 1957. A simple method for the isolation and purification of total lipides from animal tissues. J Biol Chem 226(1):497-509.

Gupta N, Goel K, Shah P, Misra A. 2012. Childhood obesity in developing countries: Epidemiology, determinants, and prevention. Endocr 33(1):48-70. https:// doi.org/10.1210/er.2010-0028

Hernandez-Trejo M, Samano R, Chico-Barba G, Pizano-Zarate L, Herrera-Gonzalez NE. 2020. Neonatal adiposity may increase plasmatic cytokines. Plos One 15(9):e02383. https://doi.org/10.1371/ journal.pone. 0238370

Jauregibeitia I, Portune K, Rica I, Teuros I, Velasco O, Grau G, Trebolazabala N, Castano L, Larocca AV, Ferreri $\mathrm{C}$ et al. 2020. Fatty acid profile of mature red blood cell membranes and dietary intake as a new approach to characterize children with overweight and obesity. Nutrients 12(11):3446. https://doi.org/10.3390/ nu12113446

Lichtenbelt WDM, Shrauwen P. 2011. Implicationsofnonshiveringthermogenesis for energy balance regulation in humans. Am J Physiol Regul Integr Comp Physiol 301:R285-R296. https://doi.org/10.1152/ ajpregu.00652.2010

Liu K, Ye K, Han Y, Sheng J, Jin Z, Bo Q, Hu C, Hu C, Li L. 2017. Maternal and cord blood fatty acid patterns with excessive gestational weight gain and neonatal macrosomia. Asia Pac J Clin Nutr 26(2): 291-297.

Luo L, Liu M. 2016. Adipose tissue in control of metabolism. J Endocrinol 231(3):R77R99. https://doi.org/10.1530/JOE-16-0211

Mennitti LV, Oliveira JL, Morais CA, Estadella D, Oyama LM, do Nascimento CMO, Pisani
LP. 2015. Type of fatty acids in maternal diets during pregnancy and/or lactation and metabolic consequences of the offspring. J Nutr Biochem 26(2):99-111. https://doi. org/10.1016/j.jnutbio.2014.10.001

Mullins CA, Gannaban RB, Khan MS, Shah $\mathrm{H}$, Siddik MAB, Hedge VK, Reddy PH, Shin AC. 2020. Neural underpinning of obesity: The role of oxidative stress and inflammation in the brain. Antioxidants 9(10):1018. https://doi.org/10.3390/ antiox9101018

[MoH RI] Ministry of Health of Republic Indonesia. 2018. Basic Health Survey Report 2018. Jakarta (ID): MoH RI.

Montgomery MK, Osborne B, Brown SHJ, Small L, Mitchell TW, Cooney GJ, Turner N. 2013. Contrasting metabolic effects of medium- versus long-chain fatty acids in skeletal muscle. J Lipid Res 54(12):33223333. https://doi.org/10.1194/jlr.M040451

Moore BF, Harrall KK, Sauder KA, Glueck DH, Dabelea D. 2020. Neonatal adiposity and childhood obesity. Pediatrics 146(3):e20200737. https://doi. org/10.1542/peds.2020-0737

Moore BF, Sauder KA, Starling AP, Hebert JR, Shivappa N, Ringham BM, Glueck DH, Dabelea D. 2018. Pro-inflammatory diets during pregnancy and neonatal adiposity in the Healthy Start Study. J Pediatr 195:121-127.e2. https://doi.org/10.1016/j. jpeds.2017.10.030

O'Donovan SM, Hourihane JO, Murray DM, Kenny LC, Khashan AS, Chaoimh Cn, Irvine AD, Kiely M. 2016. Neonatal adiposity increases the risk of atopic dermatitis during the first year of life. J Allergy Clin Immunol 137(1):108-117. https://doi.org/10.1016/j.jaci.2015.05.035

Rise P, Marangoni F, Martiello A, Colombo C, Manzoni C, Marconi C, Cattabeni F, Galli C. 2018. Fatty acid profiles of blood lipids in a population group in Tibet: Correlations with diet and environmental conditions. Asia Pac J Clin Nutr 17(1):80-85.

Ruiz-Nunez B, Dijck-Brouwer J, Muskier FAJ. 2016. The relation of saturated fatty acid with low-grade inflammation and cardiovascular disease. J Nutr Biochem 36:1-20. https://doi.org/10.1016/j. jnutbio.2015.12.007 
Salvador AM, Garcia-Maldonado E, GallegoNarbon A, Zapatera B, Vaquero MP. 2019. Fatty acid profile and cardiometabolic markers in relation with diet type and omega-3 supplementation in Spanish vegetarians. Nutrients 11(7):1659. https:// doi.org/10.3390/nu11071659

Sassa T, Kihara A. 2014. Metabolism of very long-chain fatty acids: genes and pathophysiology. Biomol Ther (Seoul) 22(2):83-92. https://doi.org/10.4062/ biomolther.2014.017

Shramko VS, Polonskaya YV, Kashtanova EV, Stakhneva EM, Ragino YI. 2020. The Short Overview on the Relevance of Fatty Acids for Human Cardiovascular Disorders. Biomolecules 10(8):1127. https://doi.org/10.3390/biom10081127

SergiD, Williams LM.2020. Potential relationship between dietary long-chain saturated fatty acids and hypothalamic dysfunction in obesity. Nutr Rev 78(4):261-277. https:// doi.org/10.1093/nutrit/nuz056

Szabo AJ. 2019. Transferred maternal fatty acids stimulate fetal adipogenesis and lead to neonatal and adult obesity. Med Hypotheses 122:82-88. https://doi. org/10.1016/j.mehy.2018.10.022

Wiechers C, Kirchhof S, Maas C, Poets CF, Franz AR. 2019. Neonatal body composition by air displacement plethysmography in healthy term singletons: A systematic review. BMC Pediatrics 19:489. https:// doi.org/10.1186/s12887-019-1867-y

Yammine SG, Naja F, Tamim H, Nasrallah M, Biessy C, Aglago EK, Matta M, Romieu I, Gunter MJ, Nasreddine L et al. 2018. Association between serum phospholipid fatty acid levels and adiposity among Lebanese adults: A cross sectional study. Nutrients 10(10):1371. https://doi. org/10.3390/nu10101371 